\title{
Single Walled Carbon Nanotubes Reinforced Intermetallic TiNi Matrix Nanocomposites by Spark Plasma Sintering
}

\author{
Badis Bendjemil ${ }^{1,2, *}$, Jamal Bougdira $^{3}$, Faming Zhang ${ }^{4,5}$, Eberhard Burkel ${ }^{4}$ \\ ${ }^{1}$ LASEA, Department of Chemistry, University of Badji-Mokhtar, Algeria \\ ${ }^{2}$ Department of Mechanical Engineering, Faculty of Science and Technology, University of 8 Mai 1945 Guelma, Algeria \\ ${ }^{3}$ Faculty of Sciences and Technologies, Institute of Jean Lamour, UMR 7198, CNRS - University of Lorraine, France \\ ${ }^{4}$ Physics of New Materials, Institute of Physics, Germany \\ ${ }^{5}$ School of Materials Science and Engineering, Southeast University, China
}

Copyright $(\mathcal{C} 2015$ by authors, all rights reserved. Authors agree that this article remains permanently open access under the terms of the Creative Commons Attribution License 4.0 International License

\begin{abstract}
We report the processing of single walled carbon nanotubes (SWCNTs) reinforced TiNi intermetallic matrix nanocomposites from $\mathrm{Ti} / \mathrm{Ni}$ and $\mathrm{SWCNTs}$ powders using spark plasma sintering (SPS)at temperatures from $1000^{\circ} \mathrm{C}$ to $1200^{\circ} \mathrm{C}$. The SWCNTs are doped into the TiNi matrix from 0.0 to $1.0 \mathrm{wt} \%$. The effect of SWCNTs reinforcement contents on the relative density, phases, microstructure and microhardness of TiNi intermetallics matrix andCNTs/TiC/TiNi nanocomposites are studied. The experimental results show that the TiNi sintered at $\mathrm{T}=$ $1200^{\circ} \mathrm{C}$ reinforced with $0.8 \mathrm{wt} \%$ SWCNTs has the highest Vicker's microhardness and relative density, which were HV $5.29 \mathrm{GPa}$ and $96 \%$, respectively. That can be explained by the precipitation of $\mathrm{TiC}$ and $\mathrm{Ti}_{2} \mathrm{Ni}$ in the matrix.This study explores the possibility of developing novel TiNi matrix nanocomposites with shape memory effect and biocompatibility.
\end{abstract}

Keywords Intermetallic-matrix Composites (IMCs), SWCNTs-reinforcement, Structural Properties, Spark Plasma Sintering, Nanocomposites, Mechanical Properties

\section{Introduction}

TiNi shape memory alloys have exceptional properties, such as the shape memory effect, pseudoelasticity and biocompatibility, which enable them to be widely used in numerous applications [1]. Recent research works have shown that TiNi alloys exhibit better wear resistance than many conventional tribological materials due to their pseudoelasticity $[2,3]$. Their rapid work hardening, good corrosion and fatigue resistance may also be beneficial [4]. Near the equiatomic concentration is well known for its shape memory effect (SME). Due to its unique physical and mechanical properties at room temperature ductility, damping effect, corrosion resistance and biocompatibility, TiNi shape memory alloys can be used for biomedical applications [5, 6]. Porous NiTi-shape memory alloy has, for example, been considered as a promising biomedical material for orthopedics and bone implant surgeries in recent years [7].

A pulse current pressure sintering equipment was used for the consolidation at various sintering temperatures of TiNi alloy powder prepared by mechanical alloying [8]. A bulk $\mathrm{Ni}-\mathrm{Ti}$ material with refined microstructure was obtained by spark plasma sintering (SPS) starting from amorphous mechanically alloyed NiTi powders [9].It has also been made to develop TiNi matrix composites to further increase the wear resistance. The reinforcing phases include $\mathrm{TiC}$ [10], $\mathrm{TiN}$ [11] and precipitated $\mathrm{Ti}_{2} \mathrm{Ni}$ [12], it is considered that the hard reinforcing phases can be used to sustain external load, while the TiNi matrix may accommodate deformation, absorb impact energy and retain hard particles.

Carbon nanotubes (CNTs) are considered to be the most effective reinforcement in metal-matrix composites for structural applications $[13,21]$ due to their extraordinary mechanical, thermal, and electrical properties and high aspect ratios. In the past, $1 \mathrm{vol} \% \mathrm{CNTs} / \mathrm{TiNi}$ composites with enhanced compressive properties and wear resistance have been fabricated by hot-press sintering [22]. The tensile properties of these CNT/TiNi composites have also been reported [23]. However, the strengthening effects of CNTs and any further effects on the shape memory of the composite have not been examined. Additionally, the five volume ratio of the CNTs has resulted in insufficient strain for measuring the shape memory effect of the CNTs/NiTi composites. 
In this paper, we describe the preparation of CNTs-reinforced TiNi matrix composites through a powder metallurgical process using CNTs, and Ni and Ti elemental powders. Spark plasma sintering (SPS), which requires a very short time to sinter metal and ceramic powders, was applied to consolidate the $\mathrm{CNTs} / \mathrm{TiNi}$ composite powder at elevate temperature at 1000 and $1200^{\circ} \mathrm{C}$ with and without additing from 0.4 to $1.0 \mathrm{wt} \%$ of (SWCNTs). The microstructure of each composite was observed, the density was determined, and its mechanical properties were studied. The chemical compositions (at.\%) of the unreinforced specimen and matrix are designed as $50 \% \mathrm{Ti}-50 \% \mathrm{Ni}$. Carbon nanotubes (CNTs) reinforced $\mathrm{TiNi}$ matrix nanocomposites were synthesized by spark plasma sintering (SPS) employing elemental powders. The phase structure, morphology and transformation behaviors were studied. Attempts have also been made to develop CNTs-TiNi matrix nanocomposites to further application in biomedical and shape memory effect. The effect of the CNTs on the mechanical properties and density of the nanocomposites was investigated.

\section{Experimental Procedure}

As starting materials commercially available powders of Ti $(<45$ micrometer, $99.7 \%$ purity), Ni $(<10$ micrometer, $99.9 \%$ purity, high purity Aldrich, Germany were used as the raw materials with sizes of around 40 micrometer, respectively. The Ti, Ni and single walled carbon nanotubes (SWCNTs with diameter $<2 \mathrm{~nm}$ ) powders were mixed in a stoichiometric molar ratio of 1:1 with additing of SWCNTs in the range of 0.4 to $1.0 \mathrm{wt} \%$ by ball milling, and then dried in vacuum. Fig. 1 presented the starting sintering powder.

The mixtures were loosely compacted into a graphite die of $20 \mathrm{~mm}$ in diameter and sintered in vacuum $(1 \mathrm{~Pa})$ at various temperatures $\left(1000-1200^{\circ} \mathrm{C}\right)$ using an SPS apparatus (Tycho lab SINTER, FCT-HP-D5, FCT, Germany) (Table 1). A constant heating rate of $100^{\circ} \mathrm{C} / \mathrm{min}$ was employed, while the applied pressure was $60 \mathrm{MPa}$. The on/off time ratio of the pulsed current was set to $12 / 2$ in each run. The maximum current reached approximately 3000 A during sintering. The soaking time at high temperatures was within $10 \mathrm{~min}$. The mixed powders used for sintering were obtained from ball milling and heterogeneous coacervation methods. The unreinforced sample and a composite with an SWCNT weight fraction of SWCNTs were fabricated by SPSat 1000, 1100 and $1200^{\circ} \mathrm{C}$ under a pressure of $60 \mathrm{MPa}$ and total cycle of $20 \mathrm{~min}$. The sintered sample was polished and the density was determined.

The phase identification and the preferred orientation of the TiNi reinforced SWCNTs crystalline grains were evaluated by X-ray diffraction analysis by Bruker (Type D4, $\mathrm{GmbH}$ ) using $\mathrm{Cu} \mathrm{K} \alpha$ radiation in the angular range of $2 \mathrm{~h}=$ 20-80 degrees at a step rate of 0.020 s to identify the crystalline phases of the sintered samples at room temperature. The morphology of the elemental powders particles and the microstructure of the sintered specimens were determined with a scanning electron microscope (FESEMTscan Vega, GmbH). The optical and FESEM micrographs will be used to determine the porosity of the sintered specimens by MIP Microstructural Analysis rocessing Software. The product was cut along the cylindrical axis by Archimedes' method using water immersion. The microhardness at the top surface and the lateral surface were measured by a diamond Vickers hardness tester. The indentation loads, ranging from 10 to $500 \mathrm{~N}$, were applied for $20 \mathrm{~s}$ for each measurement.

Table 1. Characterization of the sintered samples

\begin{tabular}{|c|c|c|c|c|c|c|}
\hline Samples & $\begin{array}{c}\mathrm{T} \\
\left({ }^{\circ} \mathrm{C}\right)\end{array}$ & $\begin{array}{c}\mathrm{T} \\
(\mathrm{min})\end{array}$ & $\begin{array}{c}\text { Heating } \\
\text { rate } \\
\left({ }^{\circ} \mathrm{C} / \mathrm{min}\right)\end{array}$ & $\begin{array}{c}\mathrm{P} \\
(\mathrm{MPa})\end{array}$ & $\begin{array}{c}\text { 50Ti-50Ni } \\
\text { with wt } \% \\
\text { SWCNTs } \\
\mathrm{d}=1 \mathrm{~nm}\end{array}$ & $\begin{array}{c}\text { Current } \\
(\mathrm{A})\end{array}$ \\
\hline SPS1 & 1200 & 20 & 100 & 60 & 00 & 3000 \\
\hline SPS2 & 1200 & 20 & 100 & 60 & 0.8 & 3000 \\
\hline SPS3 & 1000 & 20 & 100 & 60 & 0.4 & 3000 \\
\hline SPS4 & 1100 & 20 & 100 & 60 & 0.0 & 3000 \\
\hline
\end{tabular}

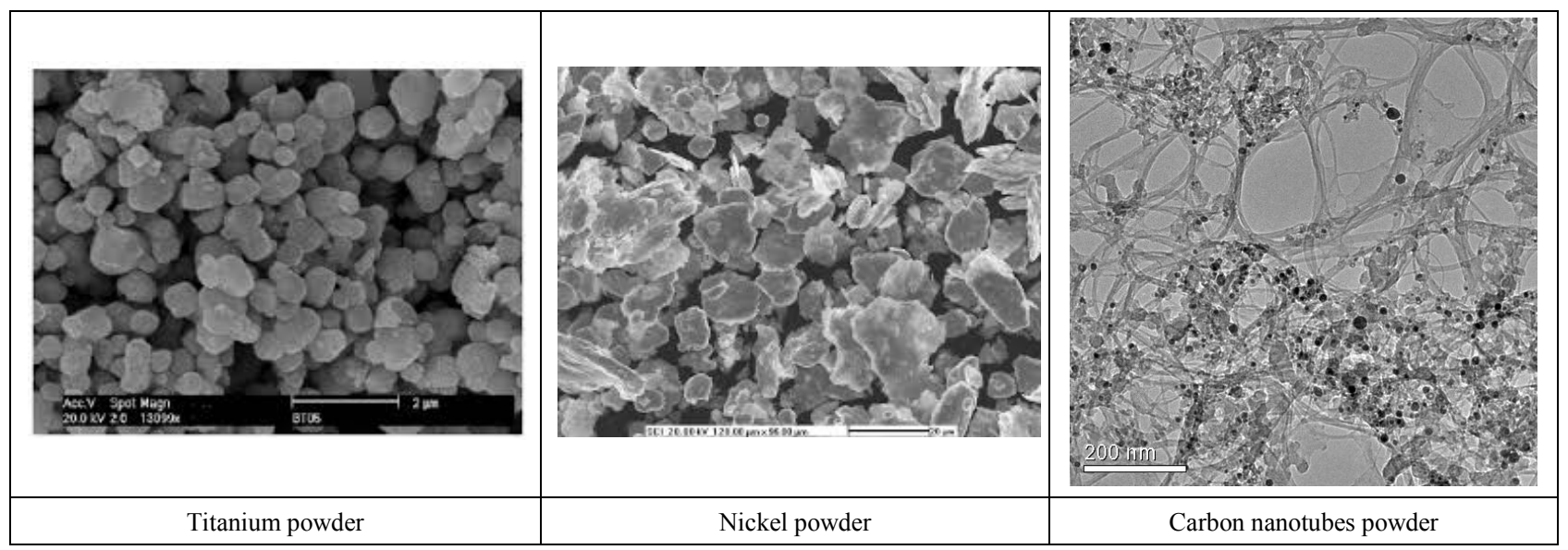

Figure 1. Starting powders before sintering 


\section{Results and Discussion}

\subsection{XRD Analysis of Powders and Sintered TiNi-SWCNTs nanocomposites}

Figure 2, 3 and 4 shows the XRD spectrum of the pure TiNi and the reinforced nanocomposite. It can be seen that the main phase is the TiNi phase, and precipitated $\mathrm{TiC}, \mathrm{Ti}_{2} \mathrm{Ni}$ phases co-exist in the three samples. XRD patterns of the $\mathrm{NiTi}$, and the nanocomposites are shown in Fig. 5. Note that the phases in the TiNi and the nanocomposites and $\mathrm{Ti}_{2} \mathrm{Ni}$. The $\mathrm{Ti}_{2} \mathrm{Ni}$ phase was formed during the sintering process in all of the samples because it is thermodynamically favorable phase at the sintering temperature compared than TiNi phase [17]:

$$
\begin{aligned}
& \mathrm{Ni}+\mathrm{Ti} \rightarrow \mathrm{NiTi}, \Delta \mathrm{G}=-176.7 \mathrm{~kJ} / \mathrm{mol} \text { at } 1173 \mathrm{~K} \\
& \mathrm{Ni}+2 \mathrm{Ti} \rightarrow \mathrm{Ti}_{2} \mathrm{Ni}, \Delta \mathrm{G}=-251.4 \mathrm{~kJ} / \mathrm{mol} \text { at } 1173 \mathrm{~K} \\
& \mathrm{Ti}+\mathrm{C} \rightarrow \mathrm{TiC}, \Delta G=-171.18 \mathrm{~kJ} / \text { molat } 1173 \mathrm{~K}
\end{aligned}
$$

XRD spectrum of the nanocomposite, which indicates that the reaction between the $\mathrm{Ti}$ powders and SWCNTs did happened during the sintering process. This reaction has been previously observed [24], and it is considered that disordered carbons on wall defects and the open ends of the SWCNTs serve as carbon sources for interfacial reaction. The sintered samples consisted mainly of TiNi matrix, as major phases, and some secondary phases, such as $\mathrm{TiC}$ and $\mathrm{Ti}_{2} \mathrm{Ni}$, appeared depending on the sintering temperature. X-ray diffraction patterns of sample $(0.8 \mathrm{Wt} \%$ CNTs-TiNi matrix nanocomposites) sintered at $60 \mathrm{MPa}$ pressure are enhanced because is reinforced with three phases $\mathrm{TiC}, \mathrm{Ti}_{2} \mathrm{Ni}$ and SWCNTs with higher intensity and is shown in Fig. 2, 3 and 4 .

Fig. 3 shows the SWCNTs content as a function of sintering temperature, which was reduced to $5 \mathrm{wt} \%$ when sintered at $1200{ }^{\circ} \mathrm{C}$ for $10 \mathrm{~min}$ at $60 \mathrm{MPa}$ pressure because is reacted with $\mathrm{Ti}$ to produce $\mathrm{TiC}$ new reinforcement.

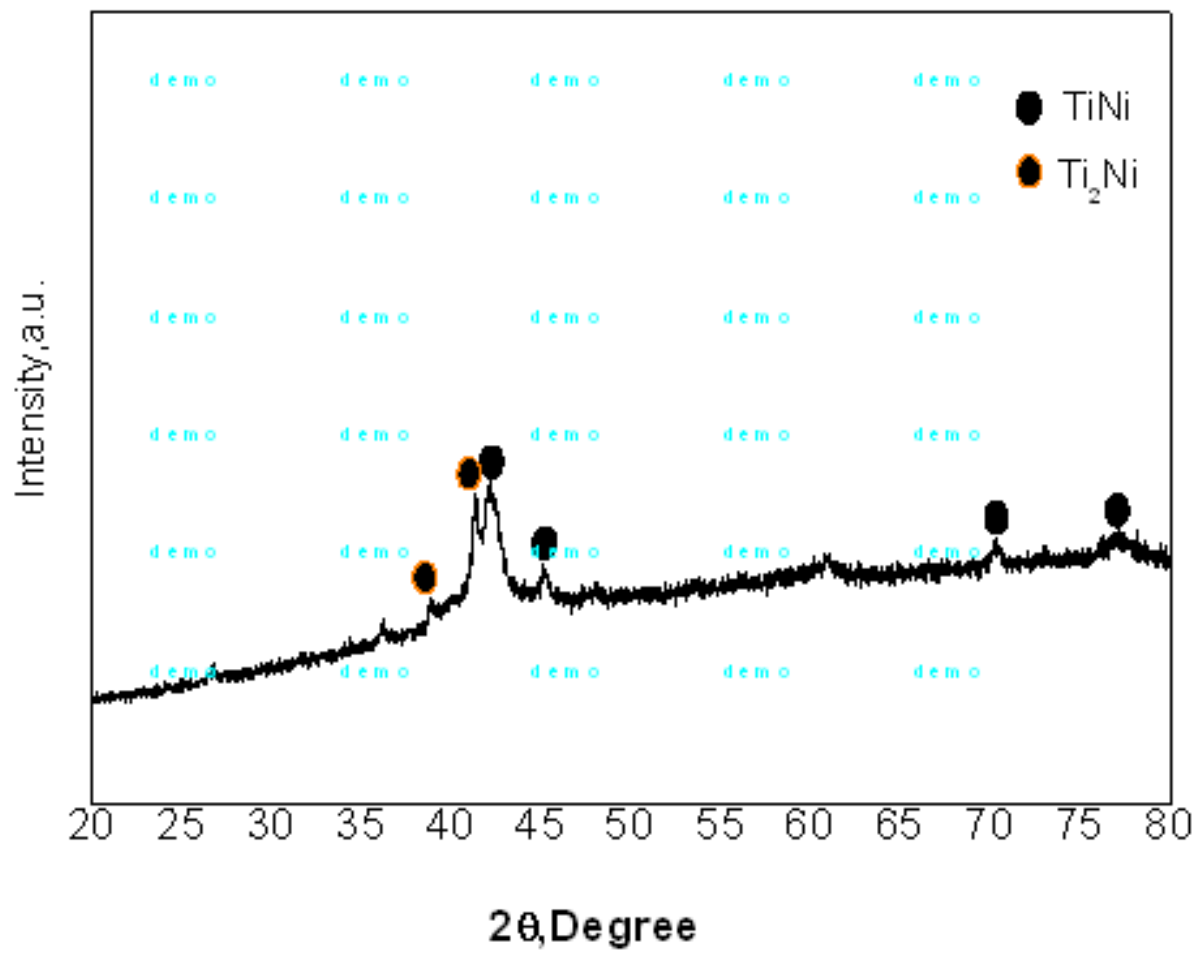

Figure 2. XRD spectra of unreinforced TiNi sintered at $\mathrm{T}=1200^{\circ} \mathrm{C}\left(\mathbf{S P S}_{\mathbf{1}}\right)$ 


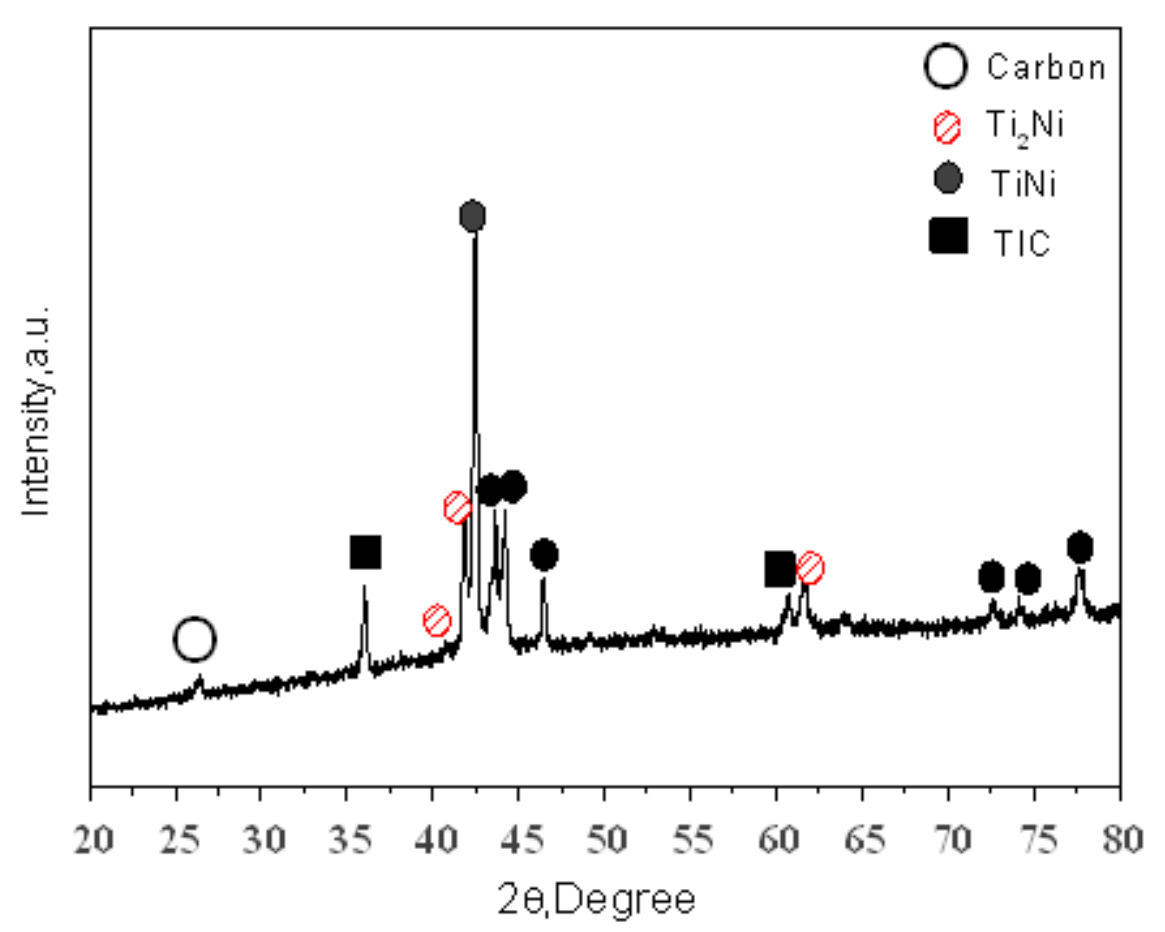

Figure 3. XRD spectra of reinforced TiNi-CNTs nanocomposites produced at $\mathrm{T}=1200^{\circ} \mathrm{C}$ reinforced with $\left.0.8 \mathrm{wt} \% \mathrm{SWCNTs}_{(\mathbf{S P S}}\right)$

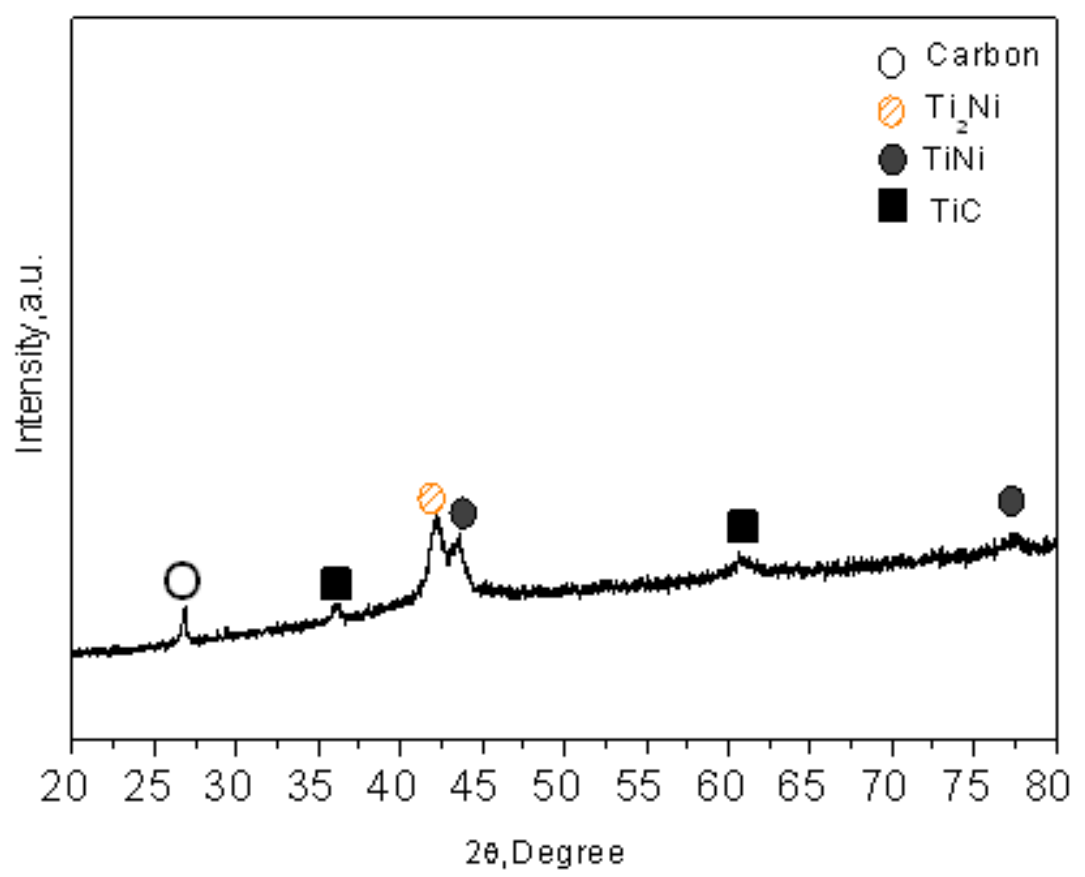

Figure 4. XRD spectra of TiNi-CNTs nanocomposites produced at $\mathrm{T}=1000^{\circ} \mathrm{C}$ reinforced with $0.4 \mathrm{wt} \% \mathrm{SWCNTs}\left(\mathbf{S P S}_{3}\right)$

\subsection{FESEM Microstructural Observation of Sintered CNTs-TiNi Nanocomposites}

The worn surfaces and wear debris are compared in Figure 4. The Microstructuraland EDS analysis displays elemental analyses of the various regions of the sintered samples $\mathrm{TiNi}$, and the CNTs/TiC/TiNi nanocomposites in chemical composition (at.\%) (Fig. 5, 6 and 7). It can be seen that, with the addition of CNTs reinforcements, the contents of Ti, Ni and $\mathrm{O}$ in the sintered samples decrease. According to the above results, it can be concluded that the wickers hardness has been improved by adding SWCNTs. Fig. 6 shows the microstructure and the EDS spectra of the TiNi, and the CNTs/TiC/TiNi nanocomposites. EDS spectra was used to determine the elemental composition of the different regions in the sample and are presented by the red specta. The SEM micrographs in Fig. 6 show a dark phase that corresponds to the TiNi matrix phase, and a lighter phase that corresponds to $\mathrm{Ti}_{2} \mathrm{Ni}$ which exists mainly at the grain boundary, $\mathrm{TiC}$ is represented by the agglomerat in cubique polycristal form in addition unreacted CNTs [16]. 


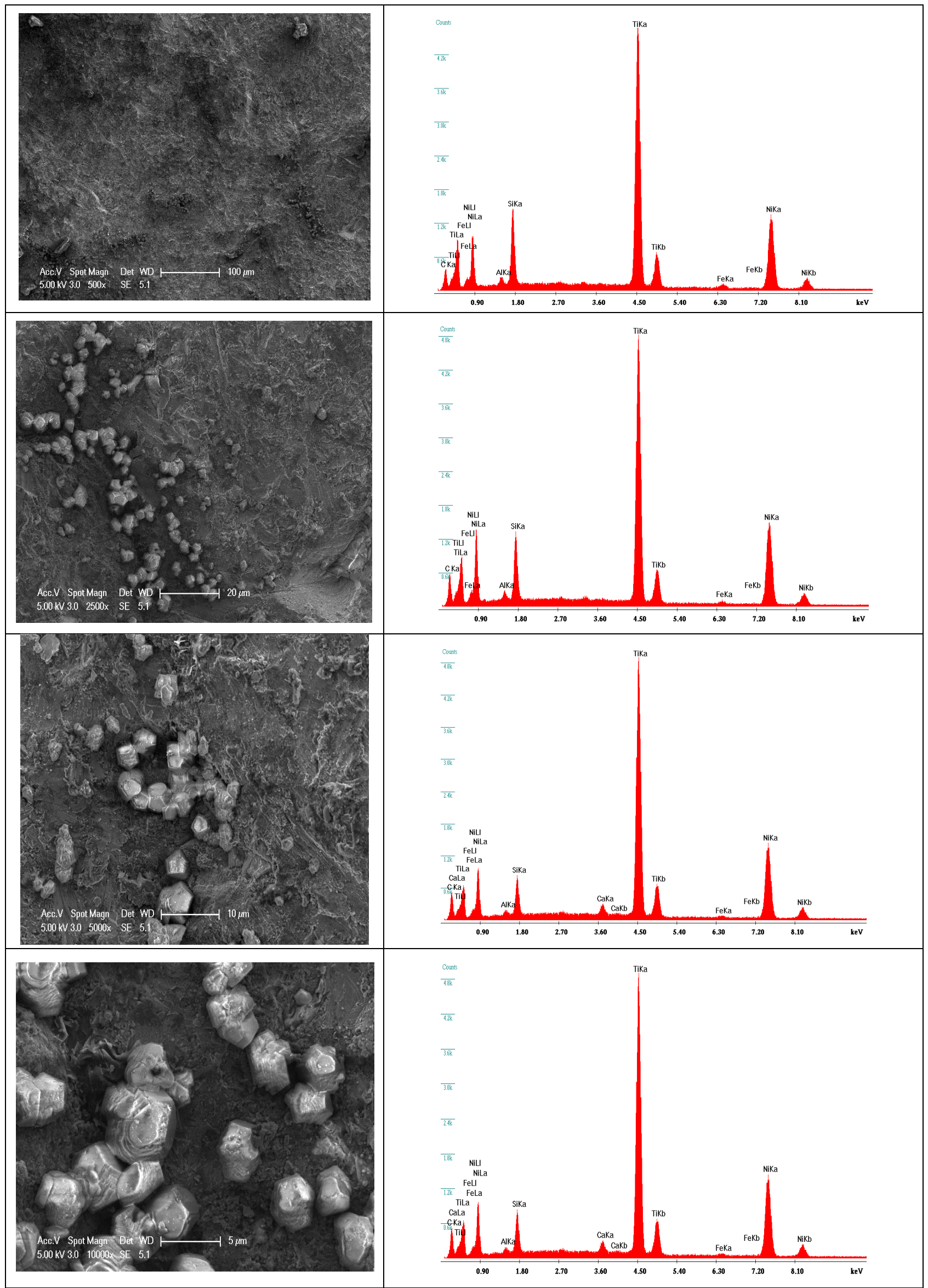

Figure5. Micrographs from the worn surfaces of unreinforced TiNi produced at $\mathrm{T}=1200^{\circ} \mathrm{C}$ 


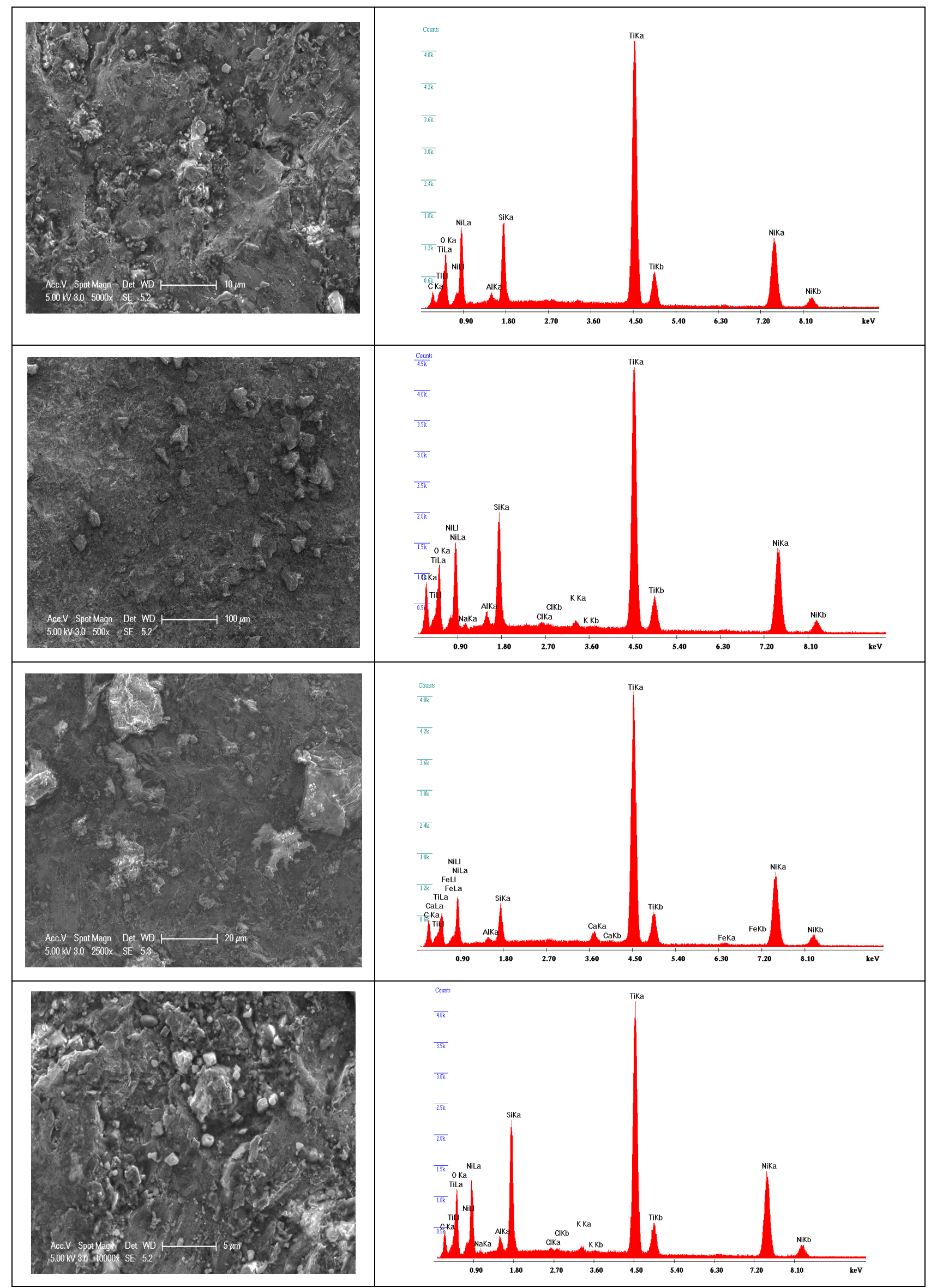

Figure 6. FESEM micrographs from the worn surfaces of TiNi-CNTs nanocomposites produced at $\mathrm{T}=1200^{\circ} \mathrm{C}$ reinforced with $0.8 \mathrm{wt} \% \mathrm{SWCNTs}$ 


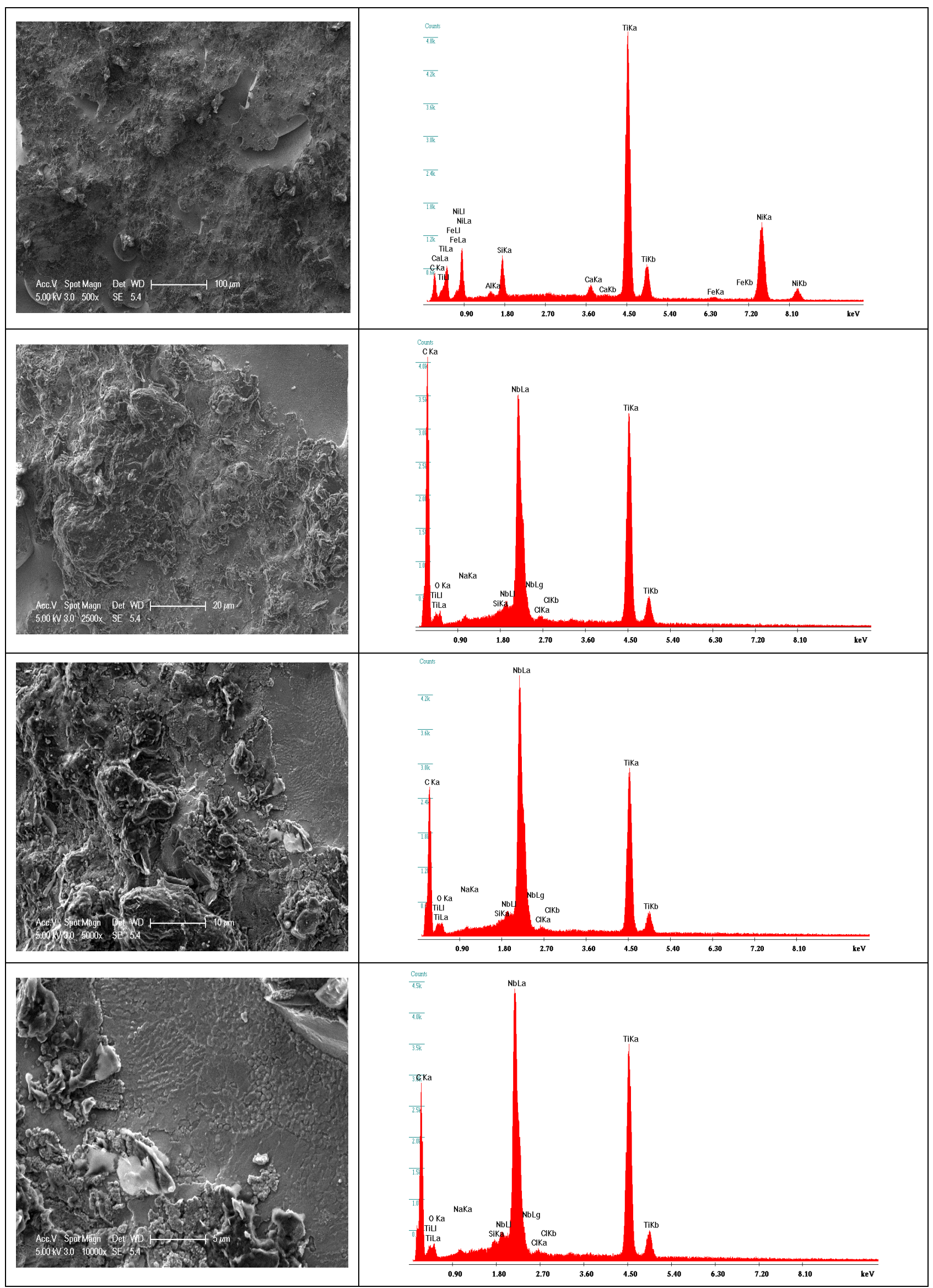

Figure 7. FESEM micrographs from the worn surfaces of TiNi-CNTs nanocomposites produced at $\mathrm{T}=1000^{\circ} \mathrm{C}$ reinforced with $0.4 \mathrm{wt} \% \mathrm{SWCNTs}$ 


\subsection{Relative Density and Microstructure}

The variation of the relaties density of sintred TiNi and TiNi-CNTs nanocomposites with SWCNTs reinforcement in schow in Fig.8, The theoritical density of the composite used for obtaining relative density was calculated using a rule of mixture using the densities of two of constituant phase $\left(\rho_{\mathrm{TiNi}}=6.55 \mathrm{~g} \mathrm{~cm}^{2}, \rho_{\mathrm{SWCNTs}}=2.25 \mathrm{~g} \mathrm{~cm}^{2}\right)$ with the given SPS processing paramaters the TiNi sample exibited best densification with relative density greater than $98 \%$, with the simlar prossessing parameters and variation of temperature CNTs-TiNi nanocomposites the relative density decresed with incressing of wt $\%$ CNTs reinforcement. The TiNiSWCNTs nanocomposites $0.8 \mathrm{wt} \% \mathrm{CNTs}$ at $\mathrm{T}=1200^{\circ} \mathrm{C}$ exibited relative density of about $95 \%$. Clearly, the CNTs reinforcement makes the densification of CNTs-TiNi nanocomposites more difficult. This seems to be direct consequence of higher melting point of SWCNTs $\left(\mathrm{T}=3160^{\circ} \mathrm{C}\right)$ compared to that of $\mathrm{TiNi}\left(\mathrm{T}=3000^{\circ} \mathrm{C}\right)$. XRD analysis indicated formation of new intermediate phase $\mathrm{TiNi}_{2}$ from there action between $\mathrm{Ti}$ and $\mathrm{Ni}$ while the intensities of SWCNTs peaks remained unchanged.

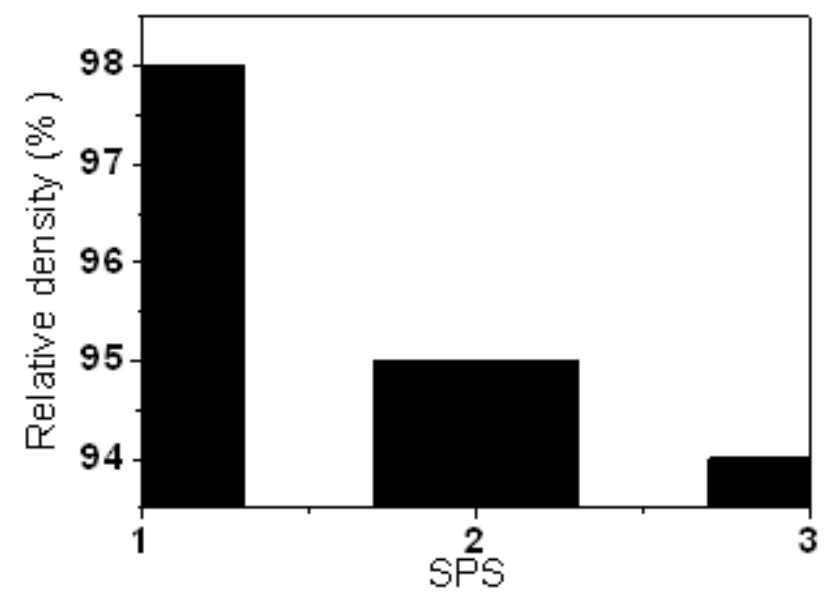

Figure 8. Relative densities of the TiNi-CNTs nanocomposites as a function of SWCNTs reinforcement content $\left(\mathbf{S P S}_{1}\right)\left(\mathbf{S P S}_{2}\right)\left(\mathbf{S P S}_{3}\right)$

Depending upon the final density to be achieved, the SPS operating condition were properly chosen, i.e. $750^{\circ} \mathrm{C}, 5$ $\mathrm{MPa}, 5 \mathrm{~min}$, to obtain a relative density of $75 \%, 800^{\circ} \mathrm{C}, 25$ $\mathrm{MPa}, 5 \mathrm{~min}$, for samples $87 \%$ dense, and $850^{\circ} \mathrm{C}, 50 \mathrm{MPa}, 5$ min, for zero porosity compacts. The $13 \%$ porosity sample exhibited a round microstructure with high ductility, while the $25 \%$ porous product displayed much lower stress flow as compared to that of the $13 \%$ porosity [24].

\subsection{Microhardness}

Fig. 9 presents the variation of Vickers microhardness of CNTs-TiNi nanocomposites with CNTs reinforcement content. The microhardness of the composites increased almost linearly with increasing of SWCNTs reinforcement content. The hardness of SWCNTs (28-30 GPa) isnearly 78 times the previously reported values of hardness of TiNi (4 GPa). For the nearly single phase TiNi SPS sintered in this investigation, the microhardness was found to be $5.96 \mathrm{GPa}$ (measured with indentation load of $10 \mathrm{~N}$ ), which is higher than the previously reported hardness values for monolithic [22]. While the higher hardness of the TiNi sample could be due to minor amount of SWCNTs phase in the TiNi sample, it could also be due to indentation size effects. It was reported that the hardness decreases with increasing load and asymptot value of $2 \mathrm{GPa}$ at higher loads. The microhardness intherange of about 2.5-3.5 GPa was find for lower loads (10 $\mathrm{N})$. The TiNi-SWCNTs nanocomposites reinforced with 0.8 wt $\%$ of SWCNTs exhibited highest hardness of about 5.56.5 GPa. A slight increase in average hardness have been obtained from TiNi matrix nanocomposites prepared by sintering 0.8 wt $\%$ single-walled carbon nanotubes (SWCNTs) with $\mathrm{Ti}$ and $\mathrm{Ni}$ elemental powders. It is considered that in situ TiC and the remaining SWCNTs act as reinforcements and plays the major role in the improvement. Finnaly the unreacted SWCNTs (Fig.5) coalesced to MWCNTs function of the temperature and process the highest hardness. It is believed that a large recoverable strain will lead to a low maximum contact pressure, and the deformation recovery can also diminish plastic deformation and retard crack propagation, thus minimizing the surface damage [18]. The formation of $\mathrm{TiC}$ is fonction of the tempetature and CNTs reinforcement as carbon source. Improved also compressive mechanical and tribo nanocomposite= properties will be tested. The memory effect and bionanocomposite compitability will also be performed in the near future. 


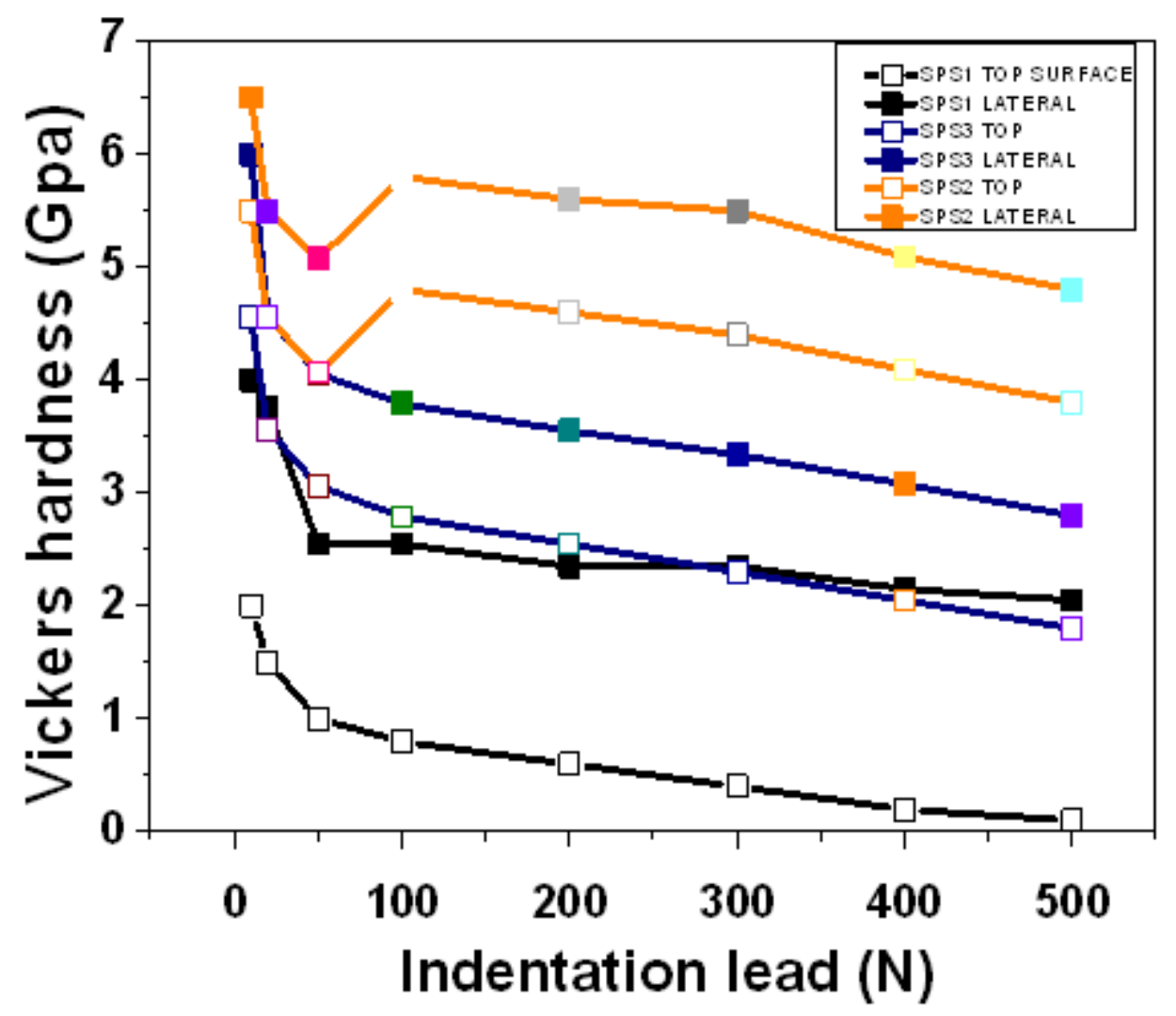

Figure 9. Vickers microhardness of TiNi-CNTs nanocomposites as a function of SWCNTs reinforcement content( $\left(\mathbf{S P S}_{1}\right)\left(\mathbf{S P S}_{2}\right)\left(\mathbf{S P S}_{3}\right)$

\section{Summary}

Dense CNTs-TiNi nanocomposites with varying weight fraction of coated CNTs were fabricated successfully by SPS in the range of 1000,1100 , and $1200^{\circ} \mathrm{C}$ under a pressure of $60 \mathrm{MPa}$ for $20 \mathrm{~min}$ in pure $\mathrm{Ar}$ atmosphere protection. The TiNi with $0.8 \mathrm{wt} \%$ SWCNTs had the highest Vicker's microhardness and relative density, which were HV 5.29 GPa and 96\%, respectively. This is increased with the CNTs addition. Although TiC was formed by reaction of CNT and Ti, unreacted CNTs could be found. Mechanical properties of TiNi were enhanced by unreacted CNTs.

\section{Acknowledgements}

We are grateful to Prof. Jaafar Gambaja, (Institut Jean Lamour, University of Henri Point Carré, Nancy, France) for his help in FESEM and XRD investigations.

\section{REFERENCES}

[1] Duerig T, Pelton A, Stockel D. An overview of nitinol medical application. Mater Sci Eng A 273-275(1999)149-60.

[2] Morgan NB. Medical shape memory alloy applications the market and its products. Mater Sci Eng A 378 (2004)16-23.
[3] Kujala Sauli. Biocompatibility and biomechanical aspects of nitinol shape memory metal implants. Finland: Department of Surgery, Department of Anatomy and Cell Biology, University of Oulu press; (2003).

[4] K. Otsuka, X. Ren, Physical metallurgy of Ti2Ni-based shape memory alloys, Progress in Materials Science 50 (2005) 511678.

[5] M. Abedini, H.M. Ghasemi, M.N. Ahmadabadi, Tribological behavior of NiTi alloy against 52100 steel and WC at elevated temperatures, Materials Characterization 61 (2010) 689-695.

[6] M. Abedini, H.M. Ghasemi, M.N. Ahmadabadi, Self-healing effect on worn surface of NiTi shape memory alloy, Materials Science and Technology 26 (2010) 285-288.

[7] Y. Shida, Y. Sugimoto, Water jet erosion behaviour of Ti-Ni binary alloys, Wear 146 (1991) 219-228.

[8] L. L. Ye, Z.G. Liu, K. Raviprasad, M. X. Quan, M. Umemoto, Z.Q. Hu, Consolidation of MA amorphous NiTi powders by spark plasma Sintering, Mater. Sci. Eng.A 241 (1998) 290-295.

[9] A. Teray ama, H. Kyogoku, M. Sakamura, S. Komatsu, Fabrication of TiNi Powder by Mechanical Alloying and Shape Memory Characteristics of the Sintered Alloy, Mater. Trans. 47 (2006) 550-557.

[10] H.Z. Ye, R. Liu, D.Y. Li, R. Eadie, Wear and friction of a new type wear-resistant material: TiNi-based composites, Scripta Mater., 41 (1999) 1039-1045

[11] Y.C. Luo, D.Y. Li, New wear-resistant material: Nano-TiN/TiC/TiNi composite, Journal of Materials Science, 36 (2001)4695-4702. 
[12] F. Gao, H.M. Wang, Effect of TiNi in dry sliding wear of laser melt deposited Ti2Ni/TiNi alloys, Intermetallics, 16 (2008) 202-208.

[13] T. Kuzumaki, K. Miyazawa, H. Ichinose, K. Ito, Processing of carbon nanotube reinforced aluminum composite , J. Mater. Res., 13 (1998)2445-2449.

[14] H. Kwon, M. Estili, K. Takagi, T. Miyazaki, A. Kawasaki, Combination of hot extrusion and spark plasma sintering for producing carbon nanotube reinforced aluminum matrix composites, Carbon, 47 (2009)570-577.

[15] W.A. Curtin, B.W. Sheldon, CNTs-reinforced ceramics and metals Mater. Today, 7 (2004)44-49.

[16] E.T. Thostenson, Z.F. Ren, T.W. Chou, Advances in the science and technology of carbon nanotubes and their composites: a review Compos. Sci. Technol., 61 (200118991912.

[17] W.X. Chen, J.P. Tu, L.Y. Wang, H.Y. Gan, Z.D. Xu, X.B., Zhang Tribological application of carbon nanotubes in a metal-based composite coating and composites Carbon, 41 (2003) 215-222.

[18] S.I. Cha, K.T. Kim, S.N. Arshad, C.B. Mo, S.H. Hong, Extraordinary strengthening effect of carbon nanotubes in metal-matrix nanocomposites processed by molecular-level mixing Adv. Mater., 17 (2005)1377-1381.

[19] D.H. Nam, S.I. Cha, B.K. Lim, H.M. Park, D.S. Han, S.H. Hong, Synergistic strengthening by load transfer mechanism and grain refinement of CNTs/Al-Cu composites Carbon, 50 (2012)2417-2423

[20] K.T. Kim, S. Il Cha, S.H. Hong, S.H., Hong Microstructures and tensile behavior of carbon nanotube reinforced $\mathrm{Cu}$ matrix nanocomposites Mater. Sci. Eng. A - Struct., 430 (2006)2733.

[21] Y.J. Jeong, S.I. Cha, K.T. Kim, K.H. Lee, C.B. Mo, S.H., Hong Synergistic strengthening effect of ultrafine-grained metals reinforced with carbon nanotubes Small, 3 (2007) 840-844.

[22] X. Feng, J.H. Sui, W. Cai, A.L. Liu, Improving wear resistance of TiNi matrix composites reinforced by carbon nanotubes and in situ TiC, Scr. Mater., 64 (2011)824-827.

[23] X. Feng, J.H. Sui, W. Cai Processing of multi-walled carbon nanotube-reinforced TiNi composites by hot pressed sintering, J. Compos. Mater., 45 (2011)1553-1557.

[24] Y. Zhao, M. Taya, H. Izui, Study on energy absorbing composite structure made of concentric NiTi spring and porous NiTi, Int. J. Solids Struct. 43 (2006)1553-1558. 